\title{
DIDÁTICA E A PRÁTICA DOCENTE NA ESCOLA BÁSICA EM UMA PERSPECTIVA CRÍTICA DE EDUCAÇÃO
}

\author{
DIDACTICS AND TEACHING PRACTICE IN BASIC SCHOOL IN A CRITICAL \\ EDUCATION PERSPECTIVE
}

\section{DIDÁCTICA Y LA PRÁCTICA DOCENTE EN LA ESCUELA PRIMARIA EN UNA PERSPECTIVA CRÍTICA DE EDUCACIÓN}

\author{
DOI: $\underline{\text { http://dx.doi.org/10.9771/gmed.v11i1.28870 }}$
}

\begin{abstract}
Osmar Hélio Alves Araújo ${ }^{1}$
Resumo: Este artigo visa discutir o papel da Didática e da prática docente na escola básica em uma perspectiva crítica de educação. Inicialmente, discutiremos a Pedagogia como ciência da/para a educação; a Didática em uma perspectiva crítica e o seu papel na formação dos professores. Em seguida, destacaremos a necessidade de práticas docentes pedagógicas que apontem para novos horizontes, novas possibilidades de abordagem do contexto social atual, novos modos de perceber/entender e intervir nessa mesma realidade. Por fim, argumentaremos a favor da articulação entre a Didática, a Pedagogia e as demais áreas das ciências que auxiliam o trabalho docente na escola básica, como um meio de assegurar uma educação inteiramente como chave transformadora da sociedade.
\end{abstract}

Palavra-chaves: Didática. Pedagogia. Prática docente. Escola básica.

Abstract: This article aims to discuss the role of Didactics and teaching practice in basic school in a critical education perspective. Initially, we will discuss Pedagogy as a science of/to education; Didactics in a critical perspective and its role in teacher training. Next, we will highlight the need for pedagogical teaching practices that point to new horizons, new possibilities to approach the current social context, new ways of perceiving/understanding and intervening in the same reality. Finally, we will argue in favor of the articulation between Didactics, Pedagogy and other Science areas that aid teaching practices in basic school, as a means to ensure education entirely as a transforming key of society.

Keywords: Didactics. Pedagogy. Teaching practice. Basic school.

Resumen: Este artículo tiene como objetivo discutir el papel de la Didáctica y de la práctica docente en la escuela primaria en una perspectiva crítica de educación. Inicialmente, discutiremos la Pedagogía como ciencia de la/para la educación; la Didáctica en una perspectiva crítica y su papel en la formación de los profesores. Seguidamente, destacaremos la necesidad de prácticas docentes pedagógicas que apunten a nuevos horizontes, nuevas posibilidades de abordaje del contexto social actual, nuevos modos de percibir/entender e intervenir en esta misma realidad. Finalmente, argumentaremos a favor de la articulación entre la Didáctica, la Pedagogía y las demás áreas de las ciencias que ayudan al trabajo docente en la escuela primaria, como un medio de asegurar una educación enteramente como llave transformadora de la sociedad.

Palabras-clave: Didáctica. Pedagogía. Práctica docente. Escuela primaria.

\section{Considerações iniciais}

Considerando ser a Pedagogia um esforço de pensar a práxis educativa e os problemas dela decorrente (RIOS, 2014), torna-se oportuno apresentar algumas indagações: o que é Pedagogia? O que é Didática? Como a Didática pode tornar possível o ensino? Qual a principal tarefa da Didática na prática/formação do professor? Como a Didática pode enfrentar hoje as enormes contradições e desafios 
postas à docência?2 Que prática escolar a Didática deve ajudar a construir e a serviço de quem e do quê? Que sujeitos/atores a Didática deve ajudar formar? Que educação a Didática deve ajudar a construir?

No contexto político-social brasileiro, sobretudo a partir do governo de Michel Temer, pósimpeachment/2016, a educação pública brasileira vem sendo exposta a uma onda de crise, encolhimento, opressão e condições péssimas, quando não irreversíveis, de sobrevivência. Tristes exemplos são a Emenda Constitucional (PEC) dos gastos públicos; a precarização, a privatização e desresponsabilização do estado em relação ao Ensino Médio a partir da Lei 13.415/17 que trata da reforma dessa etapa da educação básica a partir, sobretudo, dos interesses do empresariado nacional³; a homologação de uma Base Nacional Comum Curricular (BNCC) que não é, como já sinalizou a Anped - Associação Nacional de Pós-Graduação e Pesquisa em Educação, fruto de um efetivo, amplo e democrático debate nacional e engajado com os professores das escolas públicas brasileiras, como já sinalizou .

Como resume Mclaren (1997, p. 158), "Vivemos em tempos perigosos. Não apenas as escolas públicas estão sob um ataque massivo e coordenado, [...], mas a ideia mesma de instituição pública está se tornando crescentemente ameaçada". É forçoso admitir que os interesses da elite brasileira estão presentes, na maioria das vezes, de várias formas nas ações empreendidas pelo governo federal. Segundo Gonçalves (2017, p. 133) “[...] as ações em curso do governo têm, entre os maiores beneficiados, os empresários, como podemos perceber com as propostas de reforma da previdência, reforma trabalhista e a própria reforma do EM [Ensino médio]". Eis aí alguns dos desafios a partir dos quais considero, mais do que nunca, importante o debate sobre a Didática e a prática docente na escola básica ${ }^{4}$ em uma perspectiva crítico-reflexiva.

Considerando esta realidade sombria que vem sendo imposta à educação pública brasileira, a Didática e a prática docente na escola básica não poderão assumir um papel significativo se não em uma perspectiva de resistência, reinvenção de estratégias e mecanismos de luta, transformação e compromisso com a construção de uma educação pública digna, com qualidade e suficiente para atender às necessidades da vida em sociedade. Concordando com Freire (1996), trata-se da resistência consciente, do exercício de luta política; de indignação diante das injustiças sociais e, consequentemente, do comprometimento pela construção de uma nova sociedade.

Cabe à Didática e a prática docente contribuir para a existência de uma educação comprometida com a emancipação intelectual e política do indivíduo. Compete à Didática e a prática docente, ainda, denunciar injustiças e gestos de violência, assim como movimentos e organizações que instalam discursos e comportamentos de ódio e intolerância. Um triste exemplo são alguns dos sinais, como aponta Frigotto (2017), do Escola Sem Partido (ESP5) que já está tendo efeitos práticos na sociedade e na escola, sob o signo do medo e da violência. Nesta discussão, portanto, a problemática em foco é o papel da Didática e da prática docente na escola básica em uma perspectiva crítica de educação.

\section{A Didática e o seu papel na formação do professor}

Compreender o campo da Didática e o seu papel na formação dos professores, campo disciplinar no qual atuo, coloca-me, em princípio, diante da necessidade de explorar e problematizar a Pedagogia como 
ciência da/para a educação ${ }^{6}$. Este debate dá continuidade a discussões que tenho realizado sobre a Pedagogia, a Didática e, especialmente, sua relação indissociável com a formação dos professores (ARAÚJO; RIBEIRO, 2017; ARAÚJO; RODRIGUES; 2018).

A partir de trabalhos e pesquisas de Franco (2012), Libâneo (2010) e Rios (2014), considero que a Pedagogia volta-se essencialmente para a práxis educativa, abarca e investiga o fenômeno educativo em seus múltiplos aspectos, conteúdos e métodos, procedimentos, entre outros. A Pedagogia nos possibilita pensar a educação como práxis, unidade teoria e prática.

Concordando com Ferreira (2017), entendo práxis como um agir pedagógico autêntico, transformador e que, a partir do seu efetivo compromisso político, procura (cor)responder aos desafios dos tempos atuais, e transformar a sociedade de modo a abrir possibilidades para a existência de vida plena para todos. Segundo Ribas e Ferreira (2014, p. 135), "Dentro da escola, toda práxis é (ou deveria ser) pedagógica, posto que a escola se constitui com e a partir do pedagógico”.

A Pedagogia, como ciência da/para a educação, desde as entranhas de sua epistemologia, até a educação como processo concreto que emerge da e para a condição humana, possui gramática própria, clara epistemologia de inclusão, de emancipação do homem e de transformação do meio social (ARAÚJO, 2018b).

A Didática, de modo indissociável da Pedagogia, com foco notadamente nos processos de ensino e aprendizagem, é, sobretudo, a construção de conhecimentos que permitem a existência de um processo educativo verdadeiramente pleno de sentido ${ }^{7}$. Com isso quero dizer que, para além de um processo educativo dissociado dos problemas da realidade brasileira, de todas as crises, a Didática visa mais do que uma prática em uma perspectiva de memorização, de repetição de exercícios ou, ainda, o simples acesso/apreensão da cultura geral. O que precisamos, a todo momento, é a existência de um processo educativo integrado, unido e disposto a ler a história e os acontecimentos sociais, culturais e políticos na perspectiva da complexidade.

O indivíduo não pode encarar a vida e os fatos sociais, históricos e políticos de forma simplista, baseando-se, muitas vezes, em dualismos: a esquerda e a direita, o pobre e o rico, o branco e o preto, entre outros. Isso exige que os estudos e pesquisas do campo da Didática tornem possível um ensino que a todo momento reacenda na sociedade a esperança no futuro do país, o interesse pelo bem comum ${ }^{8}$, insira todos os cidadãos na vida política e social que cotidianamente interferi na convivência em sociedade.

Não caberá à Didática ser uma atividade neutra na formação do professor. Ela deve, necessariamente, ser uma prática que impulsiona os professores a avançar, a seguir em frente, a escapar da apatia habitual que os levam, muitas vezes, a um discurso que nada mais tem jeito. Caberá à Didática envolver os professores nas organizações populares, nas ações coletivas, políticas e pedagógicas de resistência que os permitam construir um processo de ensino verdadeiramente como prática social e pleno de sentido político e, essencialmente, como práxis educacional.

Só na prática docente como práxis, "sujeito e realidade dialogam, se transformam e são por ela transformados" (FRANCO; GILBERTO, 2011, p. 218). Considero que a Didática, atrelada à Pedagogia e as demais ciências que auxiliam o fenômeno educativo, fará, cada vez mais, a diferença à medida que 
convocar os professores para um pensar autônomo e crítico, para reflexões situadas no tempo e espaço das salas de aula, e que, por consequência, os conduzam ao discernimento e compreensão do que acontece (ou não) no interior de cada instituição.

A formação docente, de modo articulado à Pedagogia e à Didática, deve ser uma prática social, política/pedagógica que se destina à formar e a inserir os professores na práxis social, conscientizando-os do seu papel na transformação da realidade e a desbravar novos horizontes no contexto educacional brasileiro. Concordando com Informação excluída para preservar anonimato (2018), entendo formação docente como uma célula viva construída e em construção, a partir da qual o processo educativo alcança cada vez mais êxito à medida que esse processo de formação auxilia os professores na construção da práxis a partir da leitura crítica da realidade, visando a transformá-la.

A Didática quer como instrumento político, como campo teórico-prático, ou como prática social deve apontar para novas possibilidades de investigação do fenômeno ensino-aprendizagem, com clareza da realidade do contexto educacional brasileiro e, assim, contribuir com os professores diante das contradições e desafios que estão postos à docência na contemporaneidade. Entre eles, como apontam Informação excluída para preservar anonimato (2018), assegurar um processo de ensino que engaje o homem, conscientemente, na construção e reconstrução da história. Trata-se da necessidade de uma educação que marche contra todo e qualquer preconceito, rixas entre grupos sociais, discriminações, violência, exclusão e marginalização de contingentes enormes da sociedade? .

Ainda que a Didática não consiga resolver todos os problemas que circundam o fenômeno ensinoaprendizagem, é papel da Didática contribuir para a construção de um processo educativo que aproxime o indivíduo do contexto social real, dos problemas e desafios da sociedade, da condição de não-vida de milhares de sujeitos que, cotidianamente, deveria tocar à nossa condição de cidadãos, de seres humanos. E de modo especial ao contexto de exclusão e discriminação, muitas vezes, imposto às mulheres, aos negros, aos indígenas, aos Trabalhadores, aos Sem Terra (MST), aos quilombolas, aos grupos de baixa renda.

O compromisso da Didática comporta sensibilidade, preocupação e compromisso com a vida e com a existência de um sujeito que seja presença para o outro e luta para que a sociedade seja sempre melhor. Neste contexto, é papel da Didática na formação dos professores conscientizá-los da sua responsabilidade em denunciar situações de injustiças, violências e de anunciar/fortalecer a esperança por dias melhores. Esperança em uma perspectiva ética, como uma razão de ser e exercer a docência, como um projeto de educação/vida digna para todos. Como diz Freire (1992, p.10) "Há uma esperança, não importa que nem sempre audaz, nas esquinas das ruas, no corpo de cada uma e de cada um de nós. É como se a maioria da nação fosse tomada por incontida necessidade de vomitar em face de tamanha desvergonha".

A Didática precisa, e urgentemente, apostar na formação de sujeitos que não se autorreferencie, não se isolem na própria consciência ou contexto de ideias e pensamentos, assim como não se fechem num conservadorismo obstinado, desconfiado e agressivo a todo e qualquer pensamento e prática que promova e defenda a dignidade humana, independente de classe social, gênero ou crença. Mas, ao contrário, trata-se da necessidade de um sujeito que seja parte integrante/construtor de um contexto de paz, de participação e 
atuação democrática, liberdade de expressão, diálogo construtivo e que aguça o compromisso social com o bem comum.

E, igualmente, a Didática precisa ser incisiva na defesa da coerência entre a teoria e a prática na ação docente. É lamentável e triste perceber que nem sempre as belas teorias ou discursos correspondem à prática/ação de quem as anuncia/propala. Como temos enfatizado, é importante compreender que uma atuação docente autêntica implica transformações no processo educativo e não meras respostas, adaptações ou simplistas readequações visando a corresponder, sobretudo, aos interesses do sistema capitalista atual e aos pilares das ditaduras e dos reiterados golpes institucionais da classe dominante brasileira (ARAÚJO; RODRIGUES, 2018).

Diria, portanto, que a Didática deve contribuir para a existência de uma educação que tem relação com a vida, com a existência humana, plena de sentido e perpassada de esperanças, ética e compromisso social. Há muito para se investigar e fomentar o debate a respeito da Didática em uma perspectiva crítica. E isso é necessário e urgente, antes que nos roubem a alegria de ensinar-aprender; a necessária militância política-pedagógica diante de situações de injustiças sociais, da miséria moral e da indiferença de muitos em face da exploração escancarada da dignidade humana, sobretudo, a partir do "golpe parlamentar" de 2016 que empurra o Brasil a um contexto de miséria forçada ${ }^{10}$. Não deixemos que nos roubem a esperança e a crença na luta comprometida e organizada que se torna, cada vez mais, imprescindível diante de realidades de crise, opressão e violência que perpassa o contexto social-político contemporâneo.

Algo esperançoso surge no horizonte quando a Didática efetivamente dialoga com o contexto social e problematiza-o. Quer tarefa maior para a Didática, enquanto campo teórico-prático, do que encorajar e auxiliar os professores a um agir pedagógico ético, político e comprometido com a vida, com os direitos humanos, com a natureza, com as necessidades e sonhos da pessoa humana que tem, cada vez mais, seus direitos e dignidade tolhidos?

\section{A docência na educação básica como espaço de formação de e para todos}

Todo homem, e a sociedade de modo geral, necessita de uma educação consistente e comprometida com a construção/defesa contínua da humanidade, da cultura, da cidadania, da qualidade de vida para todos. Em tempos em que se cultuam às avaliações externas como contra regulação da escola pública; padronização/homogeneização de conteúdos e currículos escolares como parâmetro de qualidade; conhecimento-regulação em detrimento do conhecimento-emancipação, assim como articulação entre prêmio ou punição e os resultados das avaliações externas (ARAÚJO; RIBEIRO; CRUZ, 2018), a escola básica, muitas vezes, não vem se constituindo como um espaço verdadeiramente de formação de e para todos.

Considerando o exposto, o trabalho docente na educação básica, pautado no seu compromisso/papel científico e social, deve procurar responder as necessidades da vida em sociedade. Afirmamos ser as práticas pedagógicas docentes um espaço de gestação de novos tempos e possibilidades “[...] para atender a determinadas expectativas educacionais solicitadas/requeridas por dada comunidade 
social" (FRANCO, 2012, p. 154). Estou a tratar de práticas docentes que não põem a vida em sociedade em suas múltiplas nuanças à parte do processo educativo.

As práticas docentes, quando práticas pedagógicas ${ }^{11}$, apontam para novos horizontes, novas possibilidades de abordagem do contexto social-político contemporâneo e, por consequência, novos modos de perceber/entender e intervir nessa mesma realidade. Para que uma prática docente seja pedagógica, necessita ir à fonte, pautar-se na Pedagogia, constituir-se como práxis, ação-reflexão-ação, ação intencional, crítica e contextualizada na sociedade que a faz emergir.

Construir uma prática pedagógica implica abraçar um projeto de sociedade que se deseja construir; formar um homem consciente das implicações da conjuntura social, política e cultural na vida/sobrevivência humana, e, sobretudo, a empreender uma ação engajada na luta efetiva contra todo e qualquer tipo de dominação, exclusão e marginalização da condição humana.

Uma prática docente pedagógica inserida e contextualizada na realidade social nunca é neutra nas opções teórico-metodológicas, em relação à sociedade que deseja construir. A prática docente não-crítica, não dialogante e empenhada em transformar tudo, perde o sentido e pode torna-se, muitas vezes, instrumento que em nada transforma o ser e o agir humano. Em uma mesma perspectiva, como diz Franco (2017, p. 153), “a Pedagogia não-crítica deixa de ser Pedagogia e transforma-se em uma tecnologia social, com fins de regulação, dominação, domesticação ou mesmo doutrinação dos sujeitos a ela submetidos".

As práticas docentes deverão se (re)organizar e recriar-se sempre, plenas de sentido pedagógico, dialogantes, éticas e comprometidas com a construção de uma escola aberta às diferenças, acolhedora e empenhada na suplantação de contradições e disparidades sociais que, na maioria das vezes, mancham a dignidade humana e legitimam uma indiferença generalizada diante de milhares de mulheres, homens, jovens e crianças explorados diariamente.

É preciso apostar e lutar pela existência de uma escola pública onde a estratificação social seja quebrada e o respeito às lutas das mulheres, dos negros, dos indígenas, dos ciganos e tantas outras tão necessárias, seja alimentado, fortalecido e concretizado a favor da vida/da sobrevivência e da existência da diversidade humana. Supõe pensar/defender a existência de uma escola com identidade e autonomia pedagógica, carregada de sentido pedagógico e capaz de oportunizar um processo educativo na contramão da segregação social, do autoritarismo político, da violência, da intolerância e do ódio, entre outras práticas de opressão, marginalização e esfacelamento da condição/vida humana.

A prática docente pedagógica na escola básica precisa levar mais vida/educação digna à escola. Vida que é inclusão, acolhimento, transformação social e convivência coletiva. Isso ocorre por meio de uma prática docente cuja centralidade seja o ser humano, a (re)construção da história e a superação da violência que emana, muitas vezes, do interior do sistema capitalista.

A Didática, como área da Pedagogia, tem o desafio de fomentar a construção de uma escola que favoreça a dignidade e a cidadania, a solidariedade, a justiça e a relação ética, responsável e solidária entre as culturas, a diversidade, seja de ideias, crenças ou gênero.

A prática docente pedagógica na escola básica tem sido desafiada, sobretudo, no contexto contemporâneo, a construir uma ação transformadora da realidade à medida que novas pautas, como 
questões de gênero e sexualidade, a luta das mulheres, dos negros, dos indígenas, dos Trabalhadores, dos Sem Terra (MST), dos quilombolas, dos grupos de baixa renda, exigem, cada vez mais, uma prática docente pedagógica que não imponha-lhes hegemonia.

A docência na educação básica, mais do que nunca, deve ser instrumento político à serviço do desenvolvimento/realização plena do ser humano. Aposto na pujança da atividade docente pedagógica, a partir dos conhecimentos da Pedagogia, e das demais ciências que dialogam com a educação, para pretensiosamente construir uma escola básica como espaço verdadeiramente de formação para todos.

Preocupa-me quando a ação docente na escola básica, e a própria Didática, mantém-se à distância dos que são cotidianamente violentados, perseguidos e mortos, muitas vezes, pelos sistemas econômico, social e político. Interrogo-me, às vezes, sobre como a prática docente na escola básica e a Didática, no contexto social-político brasileiro contemporâneo, podem realmente contribuir para a existência de uma educação a serviço da plenitude humana, quando à exclusão e a injustiça, à discriminação, o preconceito, os pequenos e grandes ódios (às vezes visíveis, às vezes não) marcham pela escola12.

Poderia dizer que a Didática e a prática docente na escola básica são verdadeiramente autênticas e transformadoras quando construídas em uma perspectiva crítica e, portanto, como “[...] um elemento transcendente no qual o pensamento crítico se torna pré-condição para liberdade humana" (GIROUX, 1986, p. 36). Assim, está, cada vez mais em evidência, a necessidade de uma Didática e uma prática docente na escola básica em uma perspectiva crítica de educação!

\section{Algumas notas finais}

Sem a Pedagogia e a Didática, como entender o trabalho docente na escola básica? Como posicionar-se criticamente diante dos problemas sociais sem as contribuições teórico-metodológicas da Pedagogia e da Didática?

A prática docente na escola básica deve ser, antes de tudo, a expressão da Didática e da Pedagogia agindo, transformando e se constituindo como campo teórico-prático, dinâmico, processual, construtivo e comprometido com os problemas sociais da vida em sociedade.

É, sobretudo, não prática docente pedagógica crítica que a Didática se constitui e fomenta a articulação entre ensino, aprendizagem e contexto social. Entretanto, como diz Libâneo (2010), a Didática crítica, surgida no Brasil explicitamente no início dos anos 1980, e a Pedagogia sozinhas não são suficientes para assegurar a articulação entre o sujeito e o saber. Por isso, para além da Didática e da Pedagogia, faz-se necessário as contribuições das outras ciências associadas aos processos de ensino e aprendizagem para a formação de sujeitos no/com o mundo, assim como para o trabalho, o desenvolvimento da cultura, da cidadania, da convivência humana e das relações socioculturais.

A Didática, a Pedagogia, e as demais áreas das ciências que se articulam à educação, constituem os fios que tecem o trabalho docente na escola básica. Sem essa articulação, em uma perspectiva reflexivocrítica de ser/ver, sentir e construir o mundo, a educação não se constituirá como uma experiência que existe inteiramente como chave transformadora da sociedade. Não podemos esquecer que a reflexão/a 
criticidade contribui para uma aprendizagem significativa todas às vezes que for necessário o indivíduo pensar/repensar, a partir do quadro teórico-prático apresentado pela escola no processo educativo, a realidade social na qual está inserido, e, por consequência, agir pedagogicamente sobre ela visando transformá-la.

O olhar crítico do indivíduo deve se tornar uma força político-pedagógica de desestabilização, de enfrentamento e resistência ao contexto neoliberal que, vertiginosamente, vem institucionalizando-se e tolhendo os direitos e a dignidade humana. Isso supõe uma educação indissociável do cenário político-social contemporâneo, reinterpretando-o e produzindo a desestabilização da hegemonia neoliberal, ou seja, faz-se necessário uma educação que seja uma força de conflito no sistema neoliberal vigente.

Precisamos, por isso, de uma educação que se articule com e em favor da vida, da convivência com o diferente e que atua contra estruturas neoliberais, globalizantes, excludentes e que promovem a estratificação social, a marginalização, a opressão e a desumanização. Uma Didática e uma prática docente crítica acontecem no desabrochar de uma educação que se efetiva e se reafirma na luta pela dignidade do ser humano e seus direitos básicos, no que concerne à saúde, educação, cultura, lazer, trabalho, moradia, entre outros.

A Didática, a Pedagogia e as demais áreas das ciências devem contribuir, portanto, seja por meio do trabalho docente, ou não, para que a sociedade suplante o discurso que nada mais tem jeito e, por consequência, que renove a esperança por dias melhores e construa utopias e práxis que a proporcione a autorealização e fortaleça o compromisso com a transformação social. Eis aí uma das razões pelas quais penso existir na Didática e na prática docente crítica horizontes de novas possibilidades de promoção, defesa e fortalecimento da dignidade humana.

\section{Referências:}

ARAÚJO, Osmar Hélio Alves; RIBEIRO, Luís Távora Furtado; CRUZ, Jose Anderson Santos. Crítica e diálogo em face da relação escola versus avaliações externas. Revista Tempos e Espaços em Educação, São Cristóvão, Sergipe, Brasil, v. 11, n. 25, p. 203-214 abr./jun. 2018. Disponível em: < http://dx.doi.org/10.20952/revtee.v11i25.6895 >. Acesso em: 20 out. 2018 a.

ARAÚJO, Osmar Hélio Alves; RIBEIRO, Luís Távora Furtado. Tecendo relações entre a disciplina de Didática, a Universidade e o Contexto Escolar. Educação \& Linguagem • v. 21 • n. 2 • jul.- dez. 2017. Disponível em: < http://dx.doi.org/10.15603/2176-1043/el.v20n2p5-14 >. Acesso em: 09 nov. 2018.

ARAÚJO, Osmar Hélio Alves; RODRIGUES, Janine Marta Coelho. A formação contínua dos professores e as avaliações externas no contexto educacional brasileiro. Imagens da Educação, v. 8, n. 1, p. 1-13, 2018. Disponível em: < https://doi.org/10.4025/imagenseduc.v8i1.40831 >. Acesso em: 20 out. 2018.

ARAÚJO, Osmar Hélio Alves. Contribuições da Pedagogia para a educação pública brasileira no cenário político-social contemporâneo. Currículo sem Fronteiras, v. 18, p. 1044-1056, 2018 b. Disponível em: < http://www.curriculosemfronteiras.org/vol18iss3articles/araujo.pdf >. Acesso em: 12 jan. 2019.

ARAÚJO, Osmar Hélio Alves. Qual educação é necessária para a superação da violência e de injustiças?. Revista Teias, v. 19, n. 53, 2018a. Disponível em:<

https://doi.org/10.12957/teias.2018.32120>. Acesso em: 04 nov. 2018. 
Associação Nacional de Pós-Graduação e Pesquisa em Educação (ANPED). ANPEd e a BNCC: luta, resistência e negação. Rio de Janeiro - RJ, ANPED, 2018. Disponível em: < Disponível em: < http://www.anped.org.br/content/anped-e-bncc-luta-resistencia-e-negacao>. Acesso em: 01 dez 2018.

BRASIL. Ministério da Educação. Resolução CNE/CP n ${ }^{\circ}$ 2, de 22 de dezembro de 2017. Institui e orienta a implantação da Base Nacional Comum Curricular, a ser respeitada obrigatoriamente ao longo das etapas e respectivas modalidades no âmbito da Educação Básica. Disponível em: < http://basenacionalcomum.mec.gov.br/wpcontent/uploads/2018/04/RESOLUCAOCNE_CP222DEDEZEMBRODE2017.pdf>. Acesso em: 12 jan. 2019.

BRASIL. Presidência da República. Emenda Constitucional No 95, de 15 de dezembro de 2016. Altera o Ato das Disposições Constitucionais Transitórias, para instituir o Novo Regime Fiscal, e dá outras providências. Disponível em: <

http://www.planalto.gov.br/ccivil_03/Constituicao/Emendas/Emc/emc95.htm>. Acesso em: 12 fev. 2019.

BRASIL. Senado Federal. Lei No 13.415, de 16 de fevereiro de 2017. Disponível em: < https://www2.camara.leg.br/legin/fed/lei/2017/lei-13415-16-fevereiro-2017-784336publicacaooriginal-152003-pl.html>. Acesso em: 12 jan. 2019.

CARREIRA, Denise. NO CHÃO DA ESCOLA: conversando com famílias e profissionais da educação sobre o escola sem partido. In: Ação Educativa Assessoria, Pesquisa e Informação (Org.). A ideologia do movimento Escola Sem Partido: 20 autores desmontam o discurso. São Paulo: Ação Educativa, 2016, p. 125-136. Disponível em: < https://ctbeducars.files.wordpress.com/2017/05/livro-escola-sempartido.pdf >. Acesso em: 24 out. 2018.

FERREIRA, Liliana Soares. Pedagogia nos cursos de pedagogia? da ausência e dos impactos no trabalho pedagógico. Rev. Espaço do Currículo (online), João Pessoa, v.10, n.2, p. 174-190, mai./ago. 2017. Disponível em: < http://periodicos.ufpb.br/ojs2/index.php>. Acesso em: 09 nov. 2018.

FRANCO, Maria Amélia do Rosário Santoro; GILBERTO, Irene Jeanete Lemos. A PRÁTICA DOCENTE E A CONSTRUÇÃO DOS SABERES PEDAGÓGICOS. Revista Teias, v. 12 • n. $25 \bullet$ 212-224 • maio/ago. 2011 - Ética, Saberes \& Escola. Disponível em: < http://www.periodicos.proped.pro.br/index.php/revistateias/article/view/705>. Acesso em: 02 nov. 2018.

FRANCO, Maria Amélia do Rosário Santoro. Da necessidade/atualidade da pedagogia crítica: contributos de Paulo Freire. Revista Reflexão e Ação, Santa Cruz do Sul, v. 25, n. 2, p. 154-170, Maio./Ago. 2017. Disponível em:< http://dx.doi.org/10.17058/rea.v25i2.8891 >. Acesso em: 11 nov. 2018.

FRANCO, Maria Amélia do Rosário Santoro. Pedagogia e Prática Docente. 1. ed. São Paulo: Cortez, 2012.

FREIRE, Paulo. Pedagogia da Autonomia: Saberes Necessários à Prática Educativa. São Paulo: Paz e Terra, 1996.

FREIRE, Paulo. Pedagogia da Esperança: um reencontro com a Pedagogia do oprimido. 2. ed. Rio de Janeiro: Paz e Terra, 1992.

FRIGOTTO, Gaudêncio. A gênese das teses do Escola sem Partido: esfinge e ovo da serpente que ameaçam a sociedade e a educação. In: FRIGOTTO, G. (Org.). Escola "sem" partido: esfinge que ameaça a educação e a sociedade brasileira. Rio de Janeiro: UERJ, LPP, 2017, p. 17-34.

GIROUX, Henry. Teoria crítica e resistência em educação: para além das teorias de reprodução. Petrópolis: Vozes, 1986.

GONÇALVES, Suzane da Rocha Vieira. Interesses mercadológicos: E o "novo" ensino médio. Revista Retratos da Escola, Brasília, v. 11, n. 20, p. 131-145, jan./jun. 2017. Disponível em: < http://dx.doi.org/10.22420/rde.v11i20.753 >. Acesso em: 03 dez. 2018.

LIBÂNEO, José Carlos. A integração entre didática e epistemologia das disciplinas: uma via para a renovação dos conteúdos da didática. In: DALBEN, Angélica et al (org.). Convergências e tensões no 
campo e do trabalho docente: didática, formação de professores e trabalho docente. Belo Horizonte: Autêntica, 2010, p. 82-105.

\section{MCLAREN, Peter. Multiculturalismo crítico. São Paulo: Cortez, 1997.}

MELO, Adriana Almeida Sales de; SOUSA, Flávio Bezerra de. A agenda do mercado e a educação no governo Temer. Germinal: Marxismo e Educação em Debate, Salvador, v. 9, n. 1, p. 25-36, ago. 2017. Disponível em: < http://dx.doi.org/10.9771/gmed.v9i1.21619>. Acesso em: 09 nov. 2018.

RAMOS, Nogueira; FRIGOTTO, Gaudêncio. "Resistir é preciso, fazer não é preciso": as contrarreformas do ensino médio no Brasil. Cadernos de Pesquisa em Educação - PPGE/UFES Vitória, ES. v. 19, n. 46, p. 26-47, jul./dez. 2017. Disponível em: < https://doi.org/10.22535/cpe.v22i46.19329 >. Acesso em: 09 dez. 2018.

RIBAS, João Francisco Magno; FERREIRA, Liliana Soares. Trabalho de professores na escola como práxis pedagógica. Movimento, Porto Alegre, v. 20, n. 01, p. 125-143, jan/mar de 2014. Disponível em: < file:// C:/Users/Laptop/Downloads/40235-180506-1-PB.pdf >. Acesso em: 09 nov. 2018.

RIOS, Terezinha Azerêdo. A presença da filosofia e da ética no contexto profissional. Revista brasileira de comunicação organizacional e relações públicas, v. 5 n. 8, 2008. Disponível em: < https://doi.org/10.11606/issn.2238-2593.organicom.2008.138969>. Acesso em: 01 dez. 2018.

RIOS, Terezinha Azerêdo. Ampliar o diálogo de saberes para a docência. In: FRANCO, Maria Amélia Santoro; PIMENTA, Selma Garrido (Orgs.). DIDÁTICA: EMBATES CONTEMPORÂNEOS. $3^{\mathrm{a}} \mathrm{ed}$. São Paulo: Edições Loyola, 2014. p. 101-130.

\footnotetext{
Notas

${ }^{1}$ Mestre em Educação pelo Programa de Pós-Graduação em Educação da Universidade Federal do Ceará (UFC). Atualmente, cursa Doutorado em Educação (UFPB); é membro do Grupo de Pesquisa cadastrado junto ao CNPq: Formação Docente, História e Política Educacional (GPFOHPE - UFC). Docente no Curso de Letras do Plano Nacional de Formação de Professores da Educação Básica (PARFOR/UVA) e no Instituto Federal de Educação, Ciência e Tecnologia do Ceará (IFCE), Campus Tianguá (CE). ORCID: http://orcid.org/0000-0003-3396-8205 E-mail: osmarhelio@hotmail.com

${ }^{2}$ Considero que, muitas vezes, o governo federal brasileiro na atualidade tem se configurado como "[...] um cemitério de reformas; reformas curriculares então nem se fala" (NÓVOA, 2017, s/p.). Tais reformas, contudo, foram facilmente feitas. O mais difícil é oportunizar as condições de funcionamento para escolas e professores; assegurar o direito de todos à cidadania plena, assim como garantir-lhes melhores condições sociais por meio da educação. Logo, novos desafios são postos à docência no contexto políticosocial contemporâneo no Brasil.

3 Disponível em: <http://legis.senado.leg.br/legislacao/ListaTextoSigen.action?norma=540698\&id=14374 770\&idBinario $=15655553 \&$ mime $=$ application $/ \mathrm{rtf}>$. Acesso em: 01 nov. 2018.

4 Ver, por exemplo, "Vozes dissonantes na reforma do ensino médio". Disponível em: < http://www.anped.org.br/news/vozesdissonantes-na-reforma-do-ensino-medio >. Acesso em: 09 set. 2018.

${ }^{4}$ No texto, utilizo o termo escola básica para fazer referência à educação básica de modo global.

5 Trata-se do Movimento "Escola Sem Partido" organizado pela sociedade civil. As ideias desse movimento foram condensadas no Projeto de Lei do Senado, n. 193 de 2016 (PL 193), de autoria do Senador Magno Malta, intitulado de "Escola sem Partido". A tramitação do dito Projeto de Lei encontra-se encerrada a pedido do próprio autor. No que segue, visando a tornar a leitura fluída e agradável, optei pela sigla "ESP" para fazer referência a esse "projeto" de lei "Escola Sem Partido". Para mais informações sobre o ESP, ver: < https://www25.senado.leg.br/web/atividade/materias/-/materia/125666 > . Acesso em: 30 nov. 2018.

${ }^{6}$ Concordo com o pedagogo alemão Schimied Kowarzik quando chama a pedagogia de ciência da e para a educação.

${ }^{7}$ Como tenho argumentado, trata-se da defesa de uma educação para a inclusão, para o acolhimento, para a transformação social e a convivência coletiva. Uma educação, cuja centralidade seja o ser humano, capaz de desdobrar-se como uma prática ativa de (re) construção da história e comprometimento com a humanização e a superação da violência que emana, muitas vezes, do interior do sistema capitalista (ARAÚJO, 2018a).

${ }^{8}$ Trata-se da construção de uma sociedade justa e solidária; do bem comum, da promoção da dignidade humana, da vida feliz. Bem comum é bem coletivo, bem público (RIOS, 2008).

${ }^{9}$ É fato que um contexto perpassado de violência contra a mulher, de práticas de intolerância, racismo e homofobia, de exclusão e de desigualdades é realidade, mais do que nunca, no cenário social brasileiro. Por exemplo, mulheres e pessoas LGBT, entre outros, continuam sendo vítimas de violência doméstica, de abuso sexual, violência física, violência policial, discriminação, preconceito ou ódio de classe, de raça ou de gênero (ARAÚJO, 2018a).

${ }^{10}$ Concordo com Gonçalves (2017, p. 133) que "Em maio de 2016, o Brasil sofre um Golpe civil, jurídico e midiático, no qual a presidenta Dilma Rousseff é afastada e assume interinamente a Presidência do País o vice-presidente Michel Temer. Em agosto
} 
do mesmo ano, o Senado aprova o impeachment de Dilma Rousseff. Uma série de ações do governo começam a ser operacionalizadas e verifica-se um grande retrocesso no campo das políticas sociais e educacionais".

11 A esse respeito, ver: Franco (2012).

12 Como enfatiza Carreira (2016, p. 132), "Em nome de determinadas religiões, em muitas escolas públicas brasileiras, a intolerância, o preconceito, a ignorância e o ódio estão sendo propagados por aquelas pessoas que acreditam que somente sua religião contém a verdade sobre a vida e deve ser imposta a toda a sociedade. Essa situação tem gerado muito sofrimento, discriminações, violências e exclusão escolar".

Recebido em: 03/04/2019

Aprovado em: 01/07/2019 